\title{
Some taxonomic novelties for pyrenomycetous fungi from south- eastern Russia
}

\section{Vasilyeva LN $^{1}$ and Stephenson SL $^{2}$}

\author{
${ }^{1}$ Institute of Biology \& Soil Science, Far East Branch of the Russian Academy of Sciences, Vladivostok 690022, Russia \\ ${ }^{2}$ Department of Biological Sciences, University of Arkansas, Fayetteville, Arkansas 72701, USA
}

Vasilyeva LN, Stephenson SL 2015 - Some taxonomic novelties for pyrenomycetous fungi from south-eastern Russia. Mycosphere 6(5), 593-601, Doi 10.5943/mycosphere/6/5/8

\begin{abstract}
One new species (Nemania corylina), one new genus (Nummauxia), and two new combinations (Nummauxia succenturiata and Sarawakus bicolor) are proposed in this paper. Being rather frequent in south-eastern Russia, two of these species display a biogeographic connection with Europe, and the third species is an example of the disjunction between north-eastern Asia and eastern North America.
\end{abstract}

Key words - Ascomycota - Biscogniauxia - Nemania - Sarawakus - taxonomy

\section{Introduction}

In recent series of papers (Vasilyeva \& Stephenson 2010, 2011, 2014, Vasilyeva et al. 2012, 2013) we have emphasized the peculiar composition of the assemblages of species of pyrenomycetous fungi associated with different centers of fungal biodiversity. The most characteristic biogeographical features of this group of fungi in north-eastern Asia are (1) its connection with eastern North America and (2) the high level of endemism observed in species distributed around the Sea of Japan. However there are a number of pyrenomycetes described from Europe and also found in north-eastern Asia. Curiously, some of these species commonly occur in the latter area but are seemingly so rare in Europe that information about them is almost completely missing from European literature. Two examples of such species are considered in this paper.

\section{Materials \& methods}

The specimens considered in this paper are deposited in the Herbarium of the Institute of Biology and Soil Science (VLA). Microscopic analyses were carried out using standard techniques. Photographs were taken using a Nikon D40x (with DG macro-objective SIGMA EX 105 mm F2.8) digital camera.

\section{Taxonomy}

Nemania corylina Lar.N. Vassiljeva \& S.L. Stephenson, sp. nov. Fig. 1, 4A-B MycoBank 813800

Etymology - Refers to the substrate associated with this fungus. 

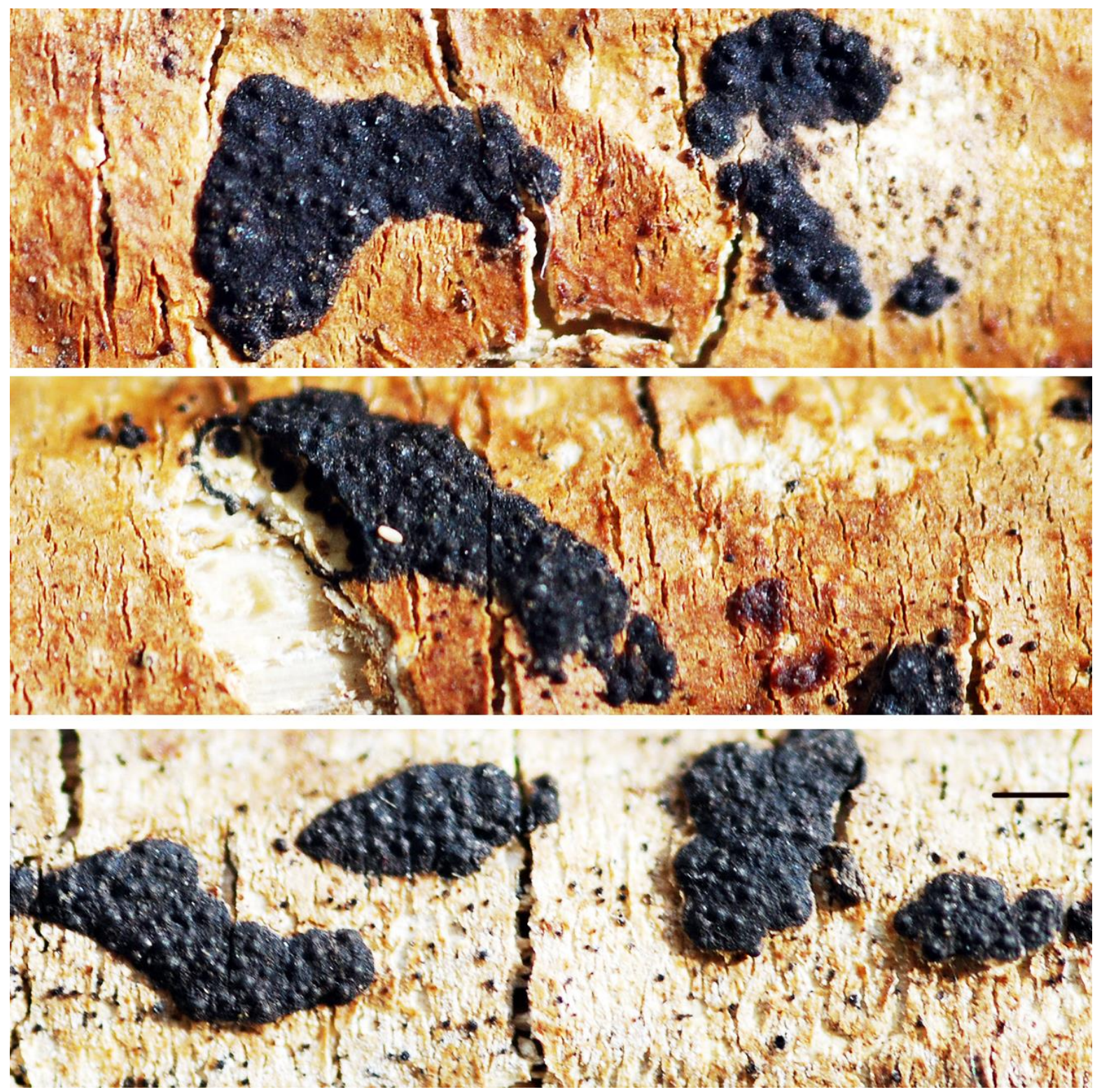

Fig. 1 - Stromata of Nemania corylina. Bar =0,75 mm.

Stromata as small and thin crusts on the surface of the inner bark of twigs, $1.5-3 \times 1-1.5 \mathrm{~mm}$, often confluent and becoming slightly larger (up to $6 \mathrm{~mm}$ long), ellipsoid, rounded or irregular, black, studded with papillate ostioles, surrounded by a black line in the substrate. Perithecia subglobose, 200-250 $\mu \mathrm{m}$ diam. Asci cylindrical, 8-spored, paraphysate, short-stipitate, in the sporebearing portion 90-115 × 10-12 $\mu \mathrm{m}$, with an apical ring bluing in Melzer's reagent, ca. 4-4.5 $\times$ 4.5-5 $\mu \mathrm{m}$. Ascospores uniseriate, one-celled, broadly-ellipsoid, brown, (13-)15-17.5 × (7-)8-10.5 $\mu \mathrm{m}$.

Known distribution - Europe, north-eastern Asia.

Material examined - Russia, Amur region, Arkhara district, Kundur vicinity, on dead branches of Corylus sp., 23 Aug 1992, L. Vasilyeva, VLA P-2890 (holotype); Tarmanchukan vicinity, on dead branches of Corylus sp., 30 Aug 1992, L. Vasilyeva, VLA P-2892. Primorsky Territory, Sikhote-Alinsky Nature Reserve, on dead branches of Corylus sp., 19 Aug 1985, L. Vasilyeva, VLA P-2891.

Notes - This species should be widely distributed in north-eastern Asia but seemingly has been overlooked because it is so inconspicuous. The species is strongly associated with branches of Corylus spp. and develops in the inner portion of the bark, becoming visible only when the outer 
layer of bark has been removed. There is some evidence that this species also occurs in Europe but has yet to be described there. On the web site http://www.shroomery.org/forums/showflat.php/Number/16108293 (visited Oct 6, 2015) under the title "black fungus on Corylus avellana," one can find a photograph (similar to those provided herein in Figure 1) and scanty information (such as "Slovenia, on very rotten wood, bark has long gone") that appear likely to refer to the species described herein.

In Table 1, data relating to the variability of ascospore size in the genus Nemania are presented. The main body of evidence was taken from the monographs by Ju and Rogers (2002) and Granmo et al. (1999). The ranges of ascospore size provided by the different authors for a particular species are mostly similar, but there are several inconsistencies. For examples, $N$. caries (Schwein.) Y.M. Ju \& J.D. Rogers and N. serpens (Pers.) Gray are considered by Ju and Rogers (2002) to have the same ranges in ascospore size (the second row in the Table 1), whereas Miller (1961) considers their width to be rather different (3-3.5 $\mu \mathrm{m}$ in $N$. caries, 5-7 $\mu \mathrm{m}$ in $N$. serpens). As such, they could be placed in different rows on the basis of ascospore width (in addition, Miller indicates a different ascospore length for the species in question: 9-12 $\mu \mathrm{m}$ in $N$. caries, $12-15 \mu \mathrm{m}$ in $N$. serpens). Also, N. effusa (Nitschke) Pouzar as described by Ju and Rogers (2002) could be placed in the first row (ascospores 2.5-3.5 $\mu \mathrm{m}$ wide), but Miller (1961) described wider ascospores $(3.5-5 \mu \mathrm{m})$ for this species (as a variety of $N$. serpens in his treatment). Nemania gwyneddii (Whalley et al.) Pouzar is listed as having ascospores 6-7.5 $\mu \mathrm{m}$ by Ju and Rogers's (2002), but the species was described originally with ascospores 7-9.5 $\mu \mathrm{m}$ wide (Whalley et al. 1983) and even indicated as having 7-11 $\mu \mathrm{m}$ as the range of width (http://pyrenomycetes.free.fr, visited 6 Oct 2015). In other words, this species might be more appropriately placed in forth row of the Table 1).

As a general observation, the data presented in Table 1 shows a rather gradual increase in ascospore width in relation to length within the genus Nemania. In other words, the shape of ascospores is more or less the same for species in this genus. In this context, $N$. corylina is prominent for its widely ellipsoid ascospores.

Table 1 Arrangement of some Nemania species in accordance with average ascospore length (columns) and width (rows)

\begin{tabular}{|c|c|c|c|c|}
\hline Width/length & 6-10 $\mu \mathrm{m}$ & $10-14 \mu \mathrm{m}$ & 15-19 $\mu \mathrm{m}$ & $20-26 \mu \mathrm{m}$ \\
\hline $3-4 \mu \mathrm{m}$ & $\begin{array}{l}\text { N. albocincta } \\
\text { N. beaumontii } \\
\text { N. effusa }\end{array}$ & N. illita & & \\
\hline $4-6 \mu \mathrm{m}$ & $\begin{array}{l}\text { N. chrysoconia } \\
\text { N. macrocarpa }\end{array}$ & $\begin{array}{l}\text { N. atropurpurea } \\
\text { N. bipapillata } \\
\text { N. carbonacea } \\
\text { N. caries } \\
\text { N. colliculosa } \\
\text { N. diffusa } \\
\text { N. immersidiscus } \\
\text { N. maritima } \\
\text { N. memorabilis } \\
\text { N. minutula } \\
\text { N. prava } \\
\text { N. reticulosa } \\
\text { N. serpens }\end{array}$ & & \\
\hline 6-7 $\mu \mathrm{m}$ & & N. ravenelii & $\begin{array}{l}\text { N. aenea } \\
\text { N. chestersii } \\
\text { N. creoleuca } \\
\text { N. latissima } \\
\text { N. subaenea }\end{array}$ & $\begin{array}{l}\text { N. gwyneddii } \\
\text { N. maculosa }\end{array}$ \\
\hline $8-12 \mu \mathrm{m}$ & & N. corylina & N. confluens & $\begin{array}{l}\text { N. angustata } \\
\text { N. quadrata } \\
\text { N. venezuelensis }\end{array}$ \\
\hline
\end{tabular}


Nummauxia Lar.N. Vassiljeva \& S.L. Stephenson, gen. nov.

MycoBank 813801

Etymology: the name is composed of the two names of genera (Nummularia and Biscogniauxia) where the type species was placed.

Stromata immersed-erumpent from the bark, diatrypelloid or lopadostomoid in appearance, wart-like, scattered, dark-brown or blackened. Perithecia elongated, arranged in a palisade layer in the upper portion of the stromata. Asci cylindrical, 8-spored, paraphysate, with an apical ring bluing in Melzer's reagent. Ascospores uniseriate, one-celled, ellipsoid, brown.

Type species: Nummauxia succenturiata (Tode) Lar.N. Vassilyeva \& S.L. Stephenson.

This genus differs from Biscogniauxia in having wart-like-diatrypelloid or lopadostomoidstromata.

Nummauxia succenturiata (Tode) Lar.N. Vassiljeva \& S.L. Stephenson, comb. nov. $\quad$ Fig. 2, 4C 三Sphaeria succenturiata Tode, Fung. Mecklenb. 2: 37, 1791.

- Hypoxylon succenturiatum (Tode) Berk. \& Broome, Ann. Mag. nat. Hist., Ser. 3(3): 363, 1859.

- Nummularia succenturiata (Tode) Nitschke, Pyrenomyc. Germ. 1: 58, 1867.

- Biscogniauxia succenturiata (Tode) Kuntze, Revis. gen. pl. 2: 398, 1891. MycoBank 813803
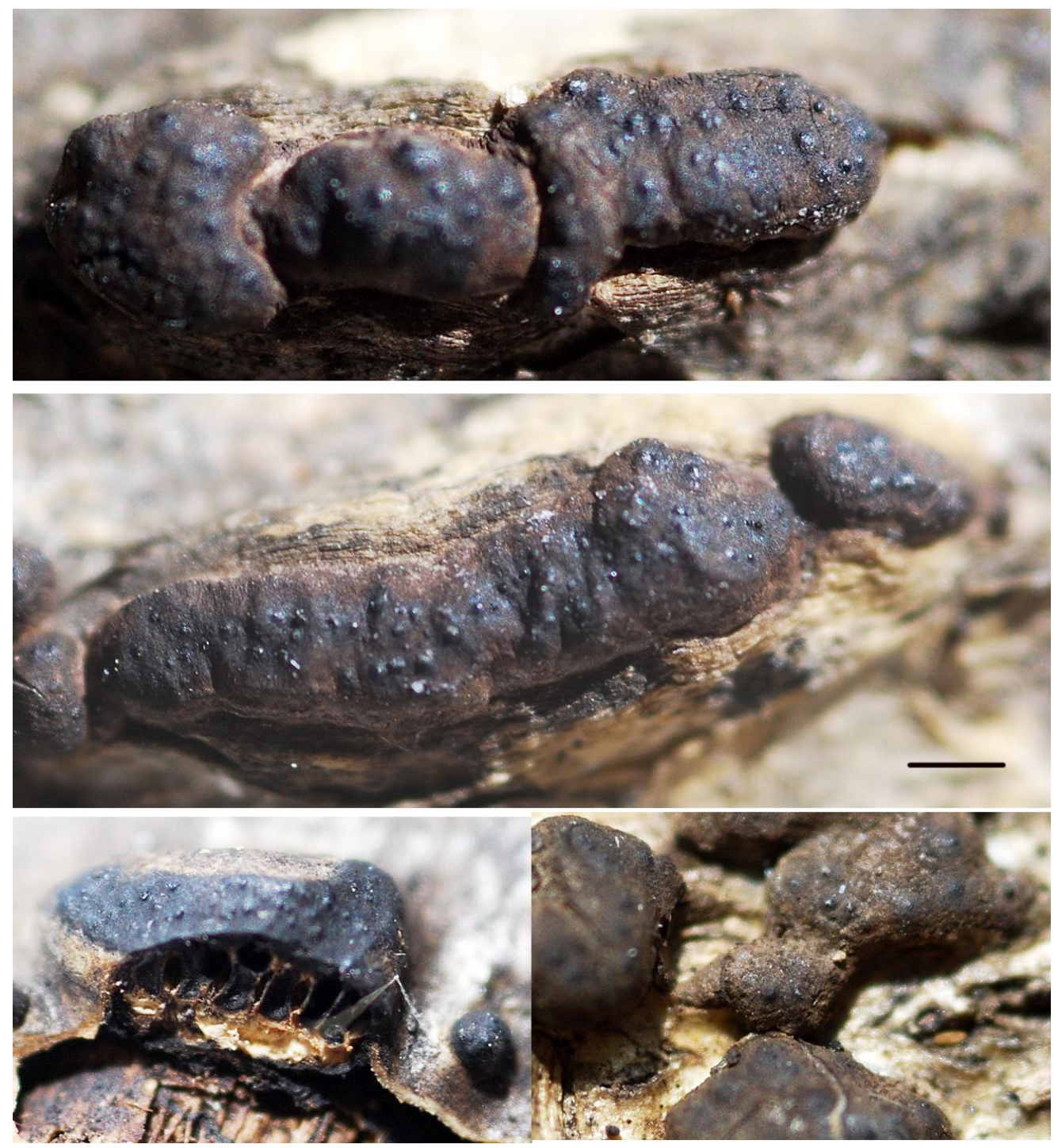

Fig. 2 - Stromata of Nummauxia succenturiata. Bar $=1.4 \mathrm{~mm}$ 
Stromata immersed-erumpent from the bark, diatrypelloid or lopadostomoid in appearance, wart-like, scattered, with coarsely papillate surface, dark-brown or blackened, 5-7(-10) $\times 2-4 \mathrm{~mm}$. Perithecia elongated, arranged in a palisade layer in the upper portion of the stromata, with whitish tissues below, 700-900 $\times 400-500 \mu \mathrm{m}$. Asci cylindrical, 8-spored, paraphysate, short-stipitate, in the spore-bearing portion 65-75 $\times 4.5-5 \mu \mathrm{m}$, with an apical ring bluing in Melzer's reagent, ca. 3$3.5 \times 2.5 \mu \mathrm{m}$. Ascospores uniseriate, one-celled, broadly-ellipsoid, brown, (9-)10-12.5 × (3.8-)4$4.5 \mu \mathrm{m}$.

Known distribution - Europe, north-eastern Asia.

Material examined - Russia, Primorsky Territory, Khasansky District, Ryazanovka vicinity, on dead branches of Quercus mongolica Fisch. ex Ledeb., 11 Aug 1991, L. Vasilyeva, VLA P1124; Kedrovaya Pad Nature Reserve, on Q. mongolica, 17 Sep 1993, L. Vasilyeva, VLA P-1127; Troitsa Bay, on Q. mongolica, 1 Nov 1995, L. Vasilyeva, VLA P-1125; Vladivostok vicinity, on $Q$. mongolica, 10 Sep 1996, L. Vasilyeva, VLA-1122. - China, Heilongjiang Province, Xingkaihu Nature Reserve, on Q. mongolica, 1 Sep 2003, L. Vasilyeva, VLA P-1444.

Notes - The type specimen of Biscogniauxia succenturiata ("Germany: Sachsen, Leipzig, Kunze, G., corticated wood, as Sphaeria succenturiata [UPS 58312]”) is said to be Lopadostoma gastrinum (Fr. : Fr.) Traverso. "However, the descriptions given by Persoon (1801), Fries (1823), and Nitschke (1867) suggest a Biscogniauxia taxon" (Ju et al. 1998, p. 81). Indeed, the early stages of B. succenturiata remind one of the stromata of L. gastrinum, and they have similar ascospores. Only later in the life history the cross-sections of stromata of B. succenturiata show the typical layer of elongated perithecia in their upper potions (Fig. 2), a feature which is characteristic of Biscogniauxia and not Lopadostoma.

Nevertheless, despite the presence of the palisade layer of the perithecia, the stromata of $B$. succenturiata never show the widely discoid or effuse types characteristic of other species of Biscogniauxia [examples are B. repanda (Fr.) Kuntze and B. nummularia (Bull.) Kuntze] and remain irregularly wart-shaped. They are somewhat similar to the stromata of Obolarina dryophila (Tul. \& C. Tul.) Pouzar, as this species is illustrated by Thomas Læssøe at www.mycokey.com (visited 6 Oct, 2015). The latter species has also been placed in the genera Nummularia and Biscogniauxia (just as B. succenturiata) and even suggested to be properly treated as Biscognauxia dryophila (Tul. \& C. Tul.) Kuntze (Nordén 2014, p. 27) because it has affinities with Biscogniauxia as confirmed by molecular studies (Pažoutova et al. 2010).

The molecular studies brought together three genera in such a way that the conclusion was made that "With Obolarina and Camillea nested inside, the genus Biscogniauxia is paraphyletic" (Pažoutova et al. 2010, p. 506). However, with an inaccurate definition of the term "paraphyletic" (cf. Hörandl \& Stuessy 2010, p. 1641), it is even more inaccurate to determine the taxonomic status of a group of species from molecular trees. They drew together the most similar forms considered for the analysis (which are often united on the similar parallel variation within closely related genera [cf. Vasilyeva \& Stephenson 2010]), and it has been correctly noted that such molecular studies are based on numerical methods (Ebach at al. 2008) and not on phylogenetic ones. To construct a true hierarchical phylogeny of taxa, one should, first of all, estimate the differences that exist among the taxa created by the analysis (cf. Vasilyeva 1999).

The genus Obolarina could be taken into consideration as a possible genus for Biscogniauxia succenturiata on the basis of the stromatal similarity mentioned above, but other published illustrations (Nordén 2014, Fig. 4; Mirabolfathy et al. 2013, Fig. 2) show the typical, widely effused stromata of Biscogniauxia in Obolarina dryophila and O. persica Mirab. et al. Therefore, $B$. succenturiata stands apart in this respect.

The main differences that have been used for the segregation of Obolarina from Biscogniauxia were the presence of spiral germination slits on the rather large ascospores, shortly clavate (succuliform) asci with an irregularly two-seriate arrangement of ascospores, and the absence of an apical ring (Pouzar 1986). These features are well illustrated by Candoussau and Rogers (1990, Figs. 5-7) and Nordén and Sunhede (2001, Fig. 3). Moreover, the illustrations show 
a stout fascicle of asci instead of the hymenial layer of asci typical for many members of the Xylariaceae. Neither of these distinguishing features of Obolarina are characteristic of Biscogniauxia succenturiata, so we segregate this species into its own genus.

Sarawakus bicolor (Ellis \& Everh.) Lar.N. Vassiljeva \& S.L. Stephenson, comb. nov. $\quad$ Fig. 3, 4D

$\equiv$ Hypocrea bicolor Ellis \& Everh., J. Mycol. 4: 58, 1888.

- Chromocreopsis bicolor (Ellis \& Everh.) Seaver, Mycologia 2: 64, 1910.

- Thuemenella bicolor (Ellis \& Everh.) Boedijn, Persoonia, 3: 3, 1964.

- Sarawakus frustulosa sensu Lar.N. Vassiljeva, Nizshie Rasteniya, Griby i Mokhoobraznye Dalnego Vostoka Rossii, Griby. Tom 4. Pirenomitsety i Loculoaskomitsety: 157, 1998, pro parte.

MycoBank 813804
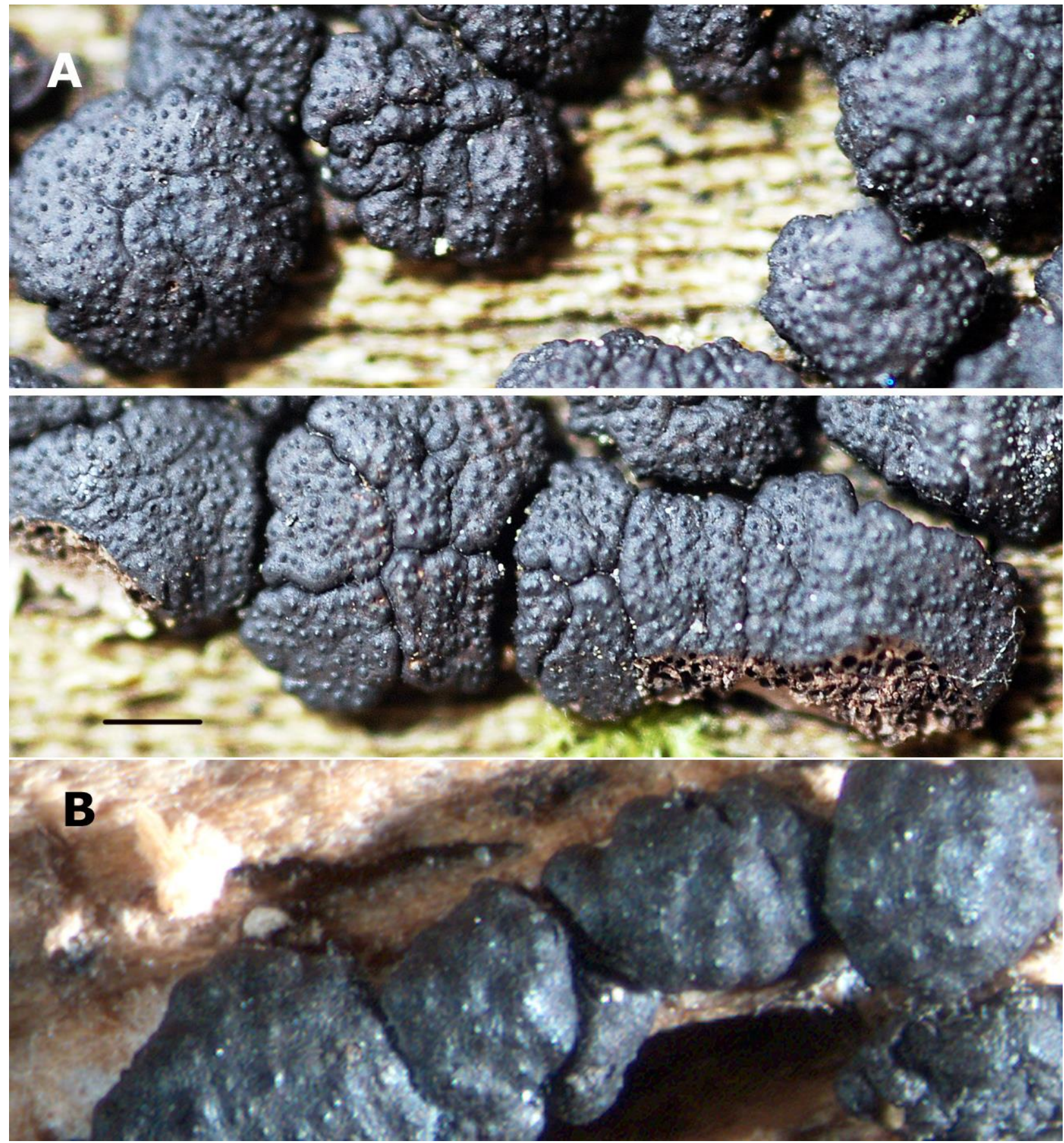

Fig. 3 - Stromata: A, Sarawakus bicolor. B, Xylaria frustulosa. Bar $=0.9 \mathrm{~mm}$. 
Stromata cushion-like, 1.5-3(-4) mm diam., broadly attached to the substrate, often confluent in large aggregates, at first reddish, later darkening to brown or almost black, whitish inside but also darkening with age to cream or brownish tinges, coarsely papillate and somewhat wrinkled at the surface. Perithecia globose, 150-200 $\mu \mathrm{m}$ diam., in the upper portion of a stroma. Asci cylindrical, 8-spored, in the spore-bearing portion $40-50 \times 3-3.5 \mu \mathrm{m}$, stalks up to $40 \mu \mathrm{m}$ long, with indistinct apical ring not bluing in Melzer's reagent. Ascospores uniseriate, one-celled, narrowellipsoid, brownish, 5-7 × 2.5-2.8 $\mu \mathrm{m}$.

Known distribution - eastern North Ameria and north-eastern Asia ('Asa-Grey disjunction).

Material examined - Russia, Primorsky Territory, Sikhote-Alin Nature Reserve, on wood, 24 Aug 1985, L. Vasilyeva, VLA P-1330; Lazo Nature Reserve, on wood, 9 Aug 1986, L. Vasilyeva, VLA P-1324; Reserve 'Kedrovaya Pad', on wood, 16 Oct 1987, L. Vasilyeva, VLA P-1329; Ussuriysk Nature Reserve, on wood, 14 Aug 1989, L. Vasilyeva, VLA P-819; Amur Region, Khingan Nature Reserve, on wood, 5 Jul 1988, L. Vasilyeva, VLA P-1327; Zeysky State Natural Reserve, on wood, 29 Jul 1988, L. Vasilyeva, VLA P-1322). - China, Heilongjiang Province, Xingkaihu Nature Reserve, on wood, 1 Sep 2003, L. Vasilyeva, VLA P-1726; Fuyuan vicinity, on wood, 5 Aug 2004, L. Vasilyeva, VLA P-1725; Jilin Province, Jiao-He vicinity, Ai-Lin forest farm, on wood, 30 Aug 2013, L. Vasilyeva, VLA P-2777.

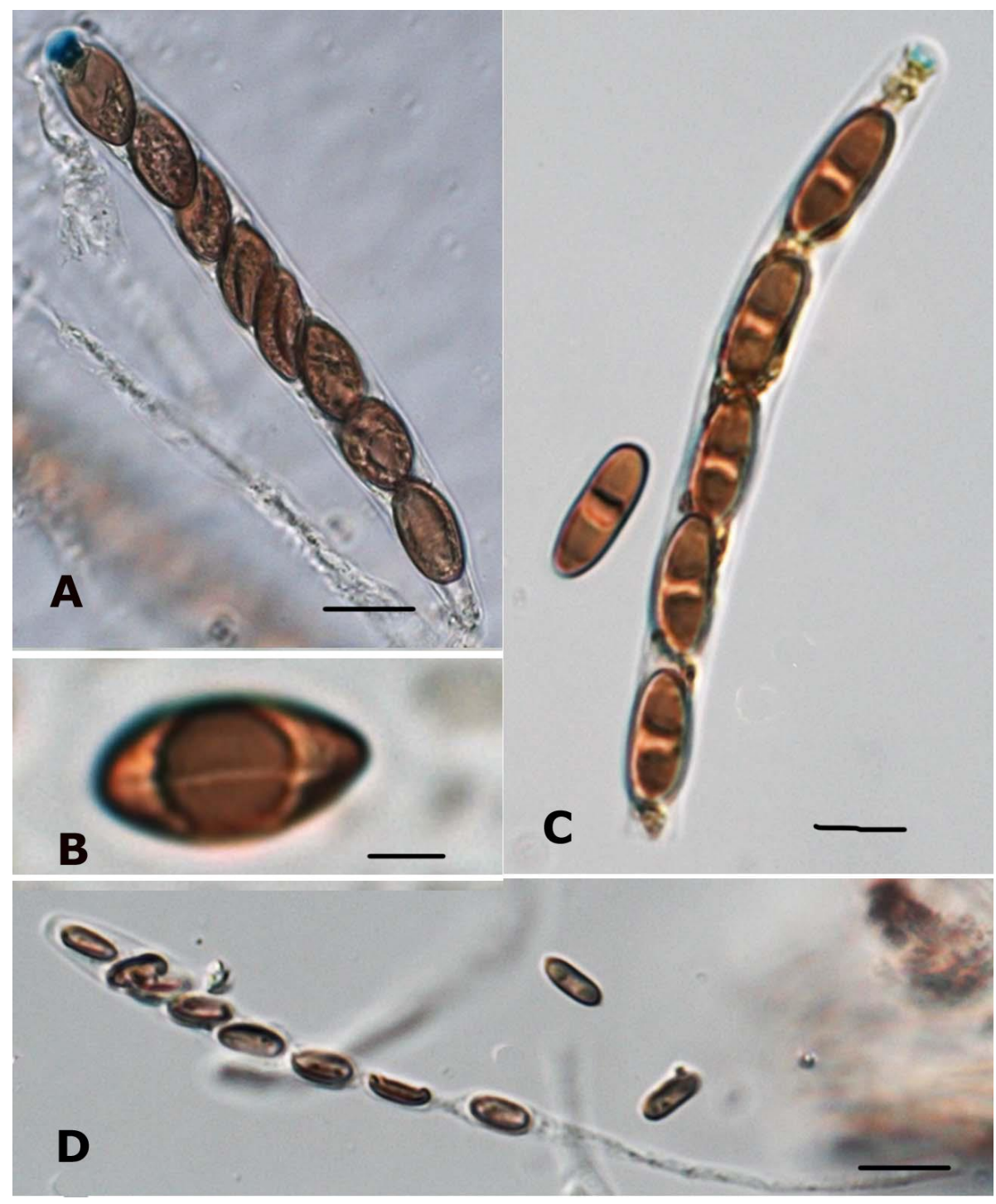

Fig. 4 - A-B, Nemania corylina: A, Ascus with ascospores. B, Ascospore with visible germ slit. C, Part of the ascus and ascospore of Nummauxia succenturiata. D, Ascus and ascospores of Sarawakus bicolor. Bars: A $=16 \mu \mathrm{m} ; \mathrm{B}=5 \mu \mathrm{m} ; \mathrm{C}=10 \mu \mathrm{m} ; \mathrm{D}=8.5 \mu \mathrm{m}$. 
Notes - This species is rather common in the southern portion of the Russian Far East and has been reported as 'Sarawakus frustulosus' (Berk. \& M.A. Curtis) Lar.N. Vassiljeva [as ' $S$. frustulosa'] (Vasilyeva 1998). The erroneous combination 'Sarawakus frustulosus' was based on the confusion of two species, namely Xylaria frustulosa (Berk. \& M.A. Curtis) Cooke and Tuemenella bicolor, both of which have small and dark stromata and colored ascospores of the same size. The type collection of T. bicolor (Kansas: Manhattan, on a log of Ulmus fulva [NY, as Hypocrea bicolor] was said to represent Xylaria frustulosa (Samuels \& Rossman 1992). This is another good example of the high degree of parallel similarity observed in different pyrenomycetous families [the case of Chromendothia citrina Lar.N. Vassiljeva and Camarops lutea (Alb. \& Schwein.) Shear was discussed previously by Vasilyeva et al. (2009)].

Despite the fact that Thuemenella bicolor is now treated as the member of the Xylariaceae (http://www.speciesfungorum.org, visited 6 Oct 2015), its hypocreaceous nature has been acknowledged by several different mycologists (Ellis \& Everhart 1888; Seaver 1910; Boedijin 1964; Vasilyeva 1998). T. bicolor from south-eastern Russia and north-eastern China, as well as from eastern North America has a disjunctive area in moderate climate of the northern hemisphere, whereas $X$. frustulosa seems to have a subtropical and tropical distribution. The name of T. bicolor refers to the changing color of stromata, which are reddish at first and then darkening later. Such a feature is not observed in $X$. frustulosa.

\section{References}

Boedijn KB. 1964 - The genus Thuemenella with remarks on Hypocreaceae and Nectriaceae. Persoonia 3, 1-7.

Candoussau F, Rogers JD. 1990 - Notes on Obolarina dryophila from France. Mycotaxon 39, 345349.

Ebach MC, Williams DM, Gill AC. 2008 - O cladistics, where art thou? Cladistics 24, 851-852.

Ellis JB, Everhart BM. 1888 - New species of fungi from various localities. Journal of mycology 4 , 49-59.

Granmo A, Læssøe T, Schumacher T. 1999 - The genus Nemania s.l. (Xylariaceae) in Norden. Sommerfeltia 27, 1-96.

Hörandl E, Stuessy TF. 2010 - Paraphyletic groups as natural units of biological classification. Taxon 59, 1641-1653.

Ju YM, Rogers JD. 2002 - The genus Nemania (Xylariaceae). Nova Hedwigia 74, 75-120.

Ju YM, Rogers JD, San Martín GF, Granmo A. 1998 - The genus Biscogniauxia. Mycotaxon 66, $1-98$.

Miller J. 1961 - A monograph of the world species of Hypoxylon. University of Georgia Press, Athens. $158 \mathrm{p}$.

Mirabolfathy M, Ju YM, Hsieh HM, Rogers JD. 2013 - Obolarina persica sp. nov., associated with dying Quercus in Iran. Mycoscience 54, 315-320.

Nordén B. 2014 - Annulohypoxylon minutellum and Obolarina dryophila (Xylariales), two stromatic pyrenomycetes on oak new to Norway. Agarica 35, 25-28.

Nordén B, Sunhede S. 2001 - Ekbarkdyna Obolarina dryophila - en doldis med intressant ekologi. Svensk Botanisk Tidskrift 95, 331-336.

Pažoutová S, Šrůtka P, Holuša J, Chudíčková M, Kolařík M. 2010 - The phylogenetic position of Obolarina dryophila (Xylariales). Mycological Progress 9, 501-507.

Pouzar Z. - 1986. A key and conspectus of Central European species of Biscogniauxia and Obolarina (Pyrenomycetes). Česká Mykologie 40, 1-10.

Samuels GJ, Rossman AY. 1992 - Thuemenella and Sarawakus. Mycologia 84, 26-40.

Seaver FJ. 1910 - The Hypocreales of North America - III. Mycologia 2, 48-92.

Vasilyeva LN. 1998 - Pyrenomycetes and loculoascomycetes. Lower plants, fungi, and bryophytes of the Russian Far East. Vol. IV. Nauka, Saint-Petersburg. 419 p. (in Russian). 
Vasilyeva L.N. 1999 - Systematics in mycology. Bibliotheca mycologica 178, 1-253.

Vasilyeva LN, Stephenson SL. 2010a - Biogeographical patterns in pyrenomycetous fungi and their taxonomy. 1. The Grayan disjunction. Mycotaxon 114, 281-303.

Vasilyeva LN, Stephenson SL. 2010b - The problems of traditional and phylogenetic taxonomy of fungi. Mycosphere 1, 45-51.

Vasilyeva LN, Stephenson SL. 2011 - Biogeographical patterns in pyrenomycetous fungi and their taxonomy. 2. Additions to the Grayan disjunction. Mycotaxon 117, 331-342.

Vasilyeva LN, Stephenson SL. 2014 - Biogeographical patterns in pyrenomycetous fungi and their taxonomy. 4. Hypoxylon and the southern United States. Mycotaxon 129, 85-95.

Vasilyeva L, Li Y, Stephenson SL. 2009 - Some pyrenomycetous fungi new to China. Mycotaxon $109,415-428$.

Vasilyeva LN, Stephenson SL, Hyde KD, Bahkali AH. 2012 - Some stromatic pyrenomycetous fungi from northern Thailand - 1. Biscogniauxia, Camillea and Hypoxylon (Xylariaceae). Fungal Diversity 55, 65-76.

Vasilyeva LN, Ma HX, Stephenson SL. 2013 - Biogeography and taxonomy of pyrenomycetous fungi 3. The area around the Sea of Japan. Mycotaxon 126, 1-14.

Whalley AJS, Edwards RL, Francis SM. 1983 - Hypoxylon gwyneddii sp. nov. from Wales. Transactions of the British Mycological Society 81, 389-392. 